\title{
Comparison of Effectiveness of Menstrual Regulation by Medication up to 6 Weeks of Gestation \& 7-9 Weeks of Gestation
}

\author{
Mirza Md. Asaduzzaman, ${ }^{1}$ Kamrun Nahar, ${ }^{2}$ Nahid Reaz, ${ }^{3}$ Shafeya Khanam, ${ }^{4}$ Shahnaz Akter Jahan, Zebunnessa Parvin, ${ }^{5}$
}

\begin{abstract}
Objective: The present study was undertaken to compare the effectiveness of menstrual regulation (MR) by medication (mifepristone and misoprostol) between women up to 6 weeks and 7-9 weeks of gestation.

Method: This prospective study was carried out in the Department of Obstetrics \& Gynaecology, Dhaka Medical College Hospital, Dhaka, over a period of 6 months from August 2014 to January 2015. Women seeking menstrual regulation (MR) services with gestational age no more than 9 weeks and confirmed intrauterine pregnancy attending at Reproductive Health Services Training and Education Program (RHSTEP) \& Gynaecology Outpatient Department of Dhaka Medical College Hospital were taken in the study. The patients were divided into two groups. One group consisted of women of gestational age up to 42 days, known as early MR (Group-I, $n=41$ ) and another group consisted of women of gestational age 43-63 days termed late MR (Group-II, $n=$ 42). The main outcome variables were time to bleeding following intervention, complete abortion and need for secondary intervention.
\end{abstract}

Result: The demographic characteristics like age, socioeconomic status, level of education and occupation were almost identically distributed between groups. The women of the two groups were almost matched in terms of their gravidity, past history of abortion or MR, use of contraceptive and indication of present MR. Time to bleeding following misoprostol administration was on an average 2 and a $1 / 2$ hours and there was no significant difference between the groups $(p=0.804)$. Over half $(51.2 \%)$ of the women up to 42 days of gestation completed abortion at or before 1st follow up visit as opposed to only $19 \%$ in late gestation group $(p=0.002)$. The need for $2^{\text {nd }}$ dose misoprostol to complete the abortion was significantly higher in the latter group than that in the former group $(p<0.001)$. The need for surgical intervention (for delayed, heavy bleeding) was comparatively less in the former group. Muscle cramping and nausea/vomiting were the most noted complications and were considerably higher in the former group. Women in the early gestation group more often reported $(17.1 \%)$ less bleeding following intervention compared to that reported by the women of late gestation $(2.4 \%)(p=0.038)$. However, pain, adverse effect and time to complete the procedure all were acceptable to the majorities of women of either group.

Conclusion: The study concluded that Menstrual Regulation with Medication (MRM) with misoprostol is effective in aborting the uterine content in women with early gestation with less bleeding and other complications. As the bleeding is more in women with late gestation, universal recommendation of its use to women with late gestation may be risky.

Key words: Menstrual regulation (MR) by medication, early MR, Late MR Outcome.

\section{Authors' information:}

${ }^{7}$ Dr. Mirza Md. Asaduzzaman, Junior Consultant, Gynae Oncology Department, National Institute of Cancer Research and Hospital (NICRH), Mohakhali, Dhaka.

${ }^{2}$ Dr. Kamrun Nahar, Consultant (Obstetrics and Gynaecology), 300 bed hospital, Narayangonj.

${ }^{3}$ Dr. Nahid Reaz, Assistant Registrar, MS (Obstetrics and Gynaecology), Central Police Hospital, Rajarbag, Dhaka, 1000.

${ }^{4}$ Dr. Shafeya Khanam, Assistant Professor, FCPS, MS (Obstetrics and Gynaecology), Faridpur Medical College \& Hospital, Faridpur.

${ }^{5}$ Dr. Shahnaz Akter Jahan, Assistant Registrar, MS (Obstetrics and Gynaecology), Central Police Hospital, Rajarbag, Dhaka, 1000.

${ }^{6}$ Dr. Zebunnessa Parvin, Associate Professor (Obstetrics and Gynaecology), MCPS, DGO, FCPS, Faridpur Medical College \& Hospital, Faridpur.

Correspondence: Dr. Mirza Md. Asaduzzaman, Cell Phone: +8801711306128, E-mail: ratandmc@gmail.com 


\section{INTRODUCTION}

Menstrual regulation (MR) is defined as any procedure which disrupts the intra uterine environment, so embryonic implantation either cannot occur or cannot be maintained ${ }^{1}$ Menstrual regulation is the management for delayed menstruation either because of clinical indication or contraception. It can be done by surgical method and medical method. The surgical method of MR can be done by manual vacuum aspiration. Although induced abortion is illegal in Bangladesh, the government has made menstrual regulation available since 1975 for the prevention of unwanted pregnancies. ${ }^{2}$

Menstrual regulation with medication (MRM) using mifepristone and misoprostol only is a safe, effective, and acceptable option for terminating pregnancies. ${ }^{3-6}$ Millions of women throughout the world have chosen MRM and find it to be a highly acceptable option. Many women describe MRM as a method that feels more natural and can be taken at home in private, thereby allowing them more control than with other methods. Women who do not have access to safe abortion are too often forced to resort to unskilled providers who work in unhygienic conditions, in many cases causing death and disability. In 2008 worldwide 21.6 million unsafe abortions took place, leading to an estimated 47,000 preventable maternal deaths. ${ }^{7}$ In low-resource settings and where access to other safe abortion methods is limited, MRM has the potential to dramatically reduce maternal morbidity and mortality.

In 1979, a legal ruling exempted MR from being regulated by the penal code and the procedure became part of the national family planning program. MR is allowed up to 10 weeks after the last menstrual period (LMP) if performed by a physician. Family welfare visitors (FWVs) and paramedics such as sub-assistant community medical officers (SACMOs) are permitted to provide MR services up to eight weeks after the LMP. In 2013, MRM was approved in Bangladesh by the National Technical Committee (NTC) of Directorate General of Family Planning (DGFP) for up to 63 days (nine weeks) of amenorrhea.
Mifepristone and misoprostol are available in the pharmacy and authorized by Bangladesh Drug Administration Authority. Mifepristone and misoprostol are increasingly used worldwide for MRM. ${ }^{8}$ Adolescent women using these medications have similar or lower rates of adverse outcomes than adult women. ${ }^{9}$

It is more accessible than vacuum aspiration because many providers can be trained to provide MRM. A study has demonstrated that appropriately trained provider can administer MRM as safely as doctors in low-resource settings. ${ }^{10}$ This makes it easier to provide care at the local level, close to where women live and work. MRM may particularly benefit young women, who are known to have reduced access to safe abortion. ${ }^{11}$ MRM may be cost-effective when compared with other methods if the most effective time slot for MRM can be established. ${ }^{12,13}$

Although MRM is already recommended and implemented by the Government, its providers are reporting discrepancy in the outcome based on gestational age with better outcome in women with early gestation (up to 42 days) than that in women with late gestation (from 43 - 63 days). However, it is still not studied whether it is equally effective in any duration of gestation up to 9 weeks. So the present study was designed to compare the outcome of menstrual regulation with medications between women with early gestation (up to 42 days) and that in women with late gestation (from 43 - 63 days). The data generated from the study will help us to identify the advantages and constraints within the program that may be helpful for further improvement of the service.

\section{MATERIALS AND METHODS}

This prospective study was conducted over a period of 6 months from August 2014 to January 2015 in the Department of Obstetrics \& Gynaecology, Dhaka Medical College, Dhaka. The main objectives were to evaluate the effectiveness of MR by medication in women up to 6 weeks and 7-9 weeks of gestation. Women seeking MR services with gestational age no more than 9 weeks (confirmed by menstrual history and 
clinical examination) were the study population. The patients were divided into two groups. One group consisting of women of gestational age up to 42 days, known as early MR group (Group-I, n $=41$ ) and another group with gestational age 43-63 days, termed as late MR group (Group-II, n $=42$ ). Data were analysed using software SPSS (Statistical Package for Social Sciences) version 16.0. The test statistics used to analyse the data were descriptive statistics, Chi-square $\left(\chi^{2}\right)$ Test and Unpaired t-Test, the level of significance was set at 0.05 and $p$-value $<0.05$ was considered significant.

\section{RESULTS}

The age distribution of the pregnant women shows that the mean age of Group-I and Group-II were $26.4 \pm 6.3$ years and $27.2 \pm 6.3$ years respectively $(p=0.575)$.

\begin{tabular}{|c|c|c|c|}
\hline \multirow[b]{2}{*}{ Demographic variables* } & \multicolumn{2}{|c|}{ Group } & \multirow[b]{2}{*}{$\mathrm{p}$-value } \\
\hline & $\begin{array}{l}\text { Group I } \\
(n=41)\end{array}$ & $\begin{array}{l}\text { Group II } \\
(n=42)\end{array}$ & \\
\hline \multicolumn{4}{|l|}{ Age (yrs) } \\
\hline$<20$ & $6(14.6)$ & $6(14.3)$ & \\
\hline $20-30$ & $24(58.5)$ & $24(57.1)$ & \\
\hline $30-40$ & $11(26.8)$ & $10(23.8)$ & \\
\hline$\geq 40$ & $0(0.0)$ & $2(4.8)$ & \\
\hline Mean \pm SD $^{\#}$ & $26.4 \pm 6.3$ & $27.2 \pm 6.3$ & 0.575 \\
\hline \multicolumn{4}{|l|}{ Socioeconomic status } \\
\hline Lower class & $12(29.3)$ & $7(16.7)$ & \multirow{3}{*}{0.283} \\
\hline Middle class & $24(58.5)$ & $26(61.9)$ & \\
\hline Rich & $5(12.2)$ & $9(21.4)$ & \\
\hline \multicolumn{4}{|l|}{ Level of education } \\
\hline Primary & $9(21.9)$ & $6(14.3)$ & \multirow{5}{*}{0.558} \\
\hline Secondary & $12(29.3)$ & $17(40.5)$ & \\
\hline Graduate & $10(24.4)$ & $8(19.0)$ & \\
\hline Post graduate & $7(17.1)$ & $10(23.8)$ & \\
\hline Others & $3(7.3)$ & $1(2.4)$ & \\
\hline \multicolumn{4}{|l|}{ Occupation } \\
\hline Housewife & $21(51.2)$ & $23(54.8)$ & \multirow{4}{*}{0.676} \\
\hline Student & $14(34.1)$ & $12(28.6)$ & \\
\hline Service & $5(12.2)$ & $6(14.3)$ & \\
\hline Others (Business and labour) & $1(2.4)$ & $1(2.4)$ & \\
\hline
\end{tabular}

Figures in the parentheses indicate corresponding \%; \# Data were analyzed using Unpaired t-Test and were presented as mean \pm SD. *Chi-squared Test $\left(\chi^{2}\right)$ was done to analyze the data.
The women of the two groups were almost identical in terms of socioeconomic status, level of education and occupation ( $p=0.283, p=0.558$ and $p=0.676$ respectively) (Table I). In terms of gravidity, majorities of the Group-I (68.3\%) and Group-II (81\%) were multigravida. The two groups were statistically matched in terms of gravidity $(p=0.185)$. The groups were also similar in terms of past history of abortion or MR $(p=0.223)$, use of contraceptive $(p=0.326)$ and indication of present MR ( $p=0.491)$ (Table II).

The mean time to bleeding following misoprostol administration was 149.5 and 153.8 minutes in Group-I and Group-II respectively ( $p=0.804$ ). Over half $(51.2 \%)$ of the women in Group-I completed abortion at or before $1^{\text {st }}$ follow up visit as opposed to only $19 \%$ in Group-II ( $p=0.002$ ). Majorities of the remaining women of either group reported abortion at $2^{\text {nd }}$ follow up visit. The need for $2^{\text {nd }}$ dose misoprostol to complete the abortion was significantly higher in the latter group than that in the former group ( $p<0.001)$. The need for surgical intervention was comparatively less in Group-I than that in Group-II ( $p=0.368$ ) (Table III).

\begin{tabular}{|c|c|c|c|}
\hline \multirow[b]{2}{*}{ Obstetric variables } & \multicolumn{2}{|c|}{ Group } & \multirow[b]{2}{*}{$\mathrm{p}$-value } \\
\hline & $\begin{array}{l}\text { Group I } \\
(n=41)\end{array}$ & $\begin{array}{l}\text { Group II } \\
(n=42)\end{array}$ & \\
\hline \multicolumn{4}{|l|}{ Gravida* } \\
\hline Primi & $13(31.7)$ & $8(19.0)$ & \multirow{2}{*}{0.185} \\
\hline Multi & $28(68.3)$ & $34(81.0)$ & \\
\hline Past history of abortion/MR* & 18(43.9) & $13(31.0)$ & 0.223 \\
\hline Use of contraceptive* & $21(51.2)$ & $26(61.9)$ & 0.326 \\
\hline \multicolumn{4}{|l|}{ Indication of $\mathrm{MR}^{* *}$} \\
\hline Medical & $2(4.9)$ & $1(2.4)$ & \multirow{2}{*}{0.491} \\
\hline Patient's request & $39(95.1)$ & $41(97.6)$ & \\
\hline
\end{tabular}

Figures in the parentheses indicate corresponding \%;

*Chi-squared Test $\left(\chi^{2}\right)$ was done to analyze the data.

**Fisher's Exact Test was done to analyze the data.

Delayed heavy bleeding was the main indication for surgical intervention (2 cases in Group-I and 4 cases in Group-II). One case in each group continued pregnancy. Muscle cramping and nausea/vomiting were the most noted 
complications and were considerably higher in the former group. Other complications diarrhoea, fever/chills and headache were no different between the groups ( $p>0.05$ ). A significantly higher proportion of women in Group-I (17.1\%) reported that the bleeding following intervention was less than they expected compared to that reported by the women of Group-II (2.4\%) ( $p=$ 0.038 ). However, pain, adverse effect and time to complete the procedure all were acceptable to the majorities of women of either group ( $p=0.506, p$ $=0.512$ and $p=0.509$ respectively) (Table IV).

\begin{tabular}{|c|c|c|c|}
\hline \multirow[b]{2}{*}{ Outcome* } & \multicolumn{2}{|c|}{ Group } & \multirow[b]{2}{*}{ p-value } \\
\hline & $\begin{array}{l}\text { Group I } \\
(n=41)\end{array}$ & $\begin{array}{l}\text { Group II } \\
(n=42)\end{array}$ & \\
\hline Time to bleeding after misoprostol (min)\# & $149.5 \pm 81.1$ & $153.8 \pm 75.8$ & 0.804 \\
\hline Abortion at $1^{\text {st }}$ follow-up visit* & $21(51.2)$ & $8(19.0)$ & 0.002 \\
\hline Abortion at $2^{\text {nd }}$ follow-up visit* & $17(41.5)$ & $31(73.8)$ & 0.003 \\
\hline $2^{\text {nd }}$ dose misoprostol needed* & $16(39.0)$ & $33(78.6)$ & $<0.001$ \\
\hline Surgical intervention needed* & $3(7.3)$ & $5(11.9)$ & 0.368 \\
\hline
\end{tabular}

Figures in the parentheses indicate corresponding \%; *Chi-squared Test $\left(\chi^{2}\right)$ was done to analyze the data. \# Data were analyzed using Unpaired $\mathbf{t}$-Test and were presented as mean \pm SD.

\begin{tabular}{|c|c|c|c|}
\hline \multirow{2}{*}{$\begin{array}{l}\text { Complications \& } \\
\text { subjective evaluation }\end{array}$} & \multicolumn{2}{|c|}{ Group } & \multirow[b]{2}{*}{ p-value } \\
\hline & $\begin{array}{l}\text { Group I } \\
(n=41)\end{array}$ & $\begin{array}{l}\text { Group II } \\
(n=42)\end{array}$ & \\
\hline \multicolumn{4}{|l|}{ Complications } \\
\hline Cramping* & $16(39.0)$ & $12(28.6)$ & 0.314 \\
\hline Nausea/vomiting ${ }^{*}$ & $22(54.7)$ & $16(38.1)$ & 0.323 \\
\hline Diarrhea** & $1(2.4)$ & $1(2.4)$ & 0.747 \\
\hline Fever/chills** & $0(0.0)$ & $1(2.4)$ & 0.506 \\
\hline Headache ${ }^{* *}$ & $3(7.3)$ & $0(0.0)$ & 0.116 \\
\hline \multicolumn{4}{|l|}{ Subjective evaluation } \\
\hline \multicolumn{4}{|l|}{ Amount of bleeding* } \\
\hline Less than expected & $7(17.1)$ & $1(2.4)$ & \\
\hline Same as expected & $33(80.5)$ & $37(88.1)$ & 0.038 \\
\hline More than expected & $1(2.4)$ & $4(9.5)$ & \\
\hline Pain acceptable** & $41(100.0)$ & $41(97.6)$ & 0.506 \\
\hline Adverse effect acceptable** & 39(95.1) & 39(92.9) & 0.512 \\
\hline Time to complete the procedure acceptable** & $40(97.6)$ & $40(95.2)$ & 0.509 \\
\hline
\end{tabular}

Figures in the parentheses indicate corresponding \%; *Chi-squared Test $\left(\chi^{2}\right)$ was done to analyze the data. **Fisher's Exact Test was done to analyzed the data.

\section{DISCUSSION}

The result presented in the earlier section should have to be compared and contrasted with similar studies conducted at home or abroad to come to a meaningful conclusion. But literature search using all the available means did not reveal a head-to-head scientific publication. In the present study the age and other demographic characteristics like socioeconomic status, level of education and occupation were almost identically distributed between early and late gestation groups. The women were mostly multigravida and there was no significant difference between the groups in terms of gravidity. The women of the two groups were almost matched in terms of past history of abortion or MR ( $p=0.223)$, use of contraceptive $(p=0.326)$ and indication of present MR ( $p=0.491)$.

The outcome obtained demonstrated that time to bleeding following misoprostol administration was on an average 2 and $a 1 / 2$ hours and there was no significant difference between the groups ( $p=$ $0.804)$. Over half $(51.2 \%)$ of the women up to 42 days of gestation completed abortion at or before $1^{\text {st }}$ follow up visit as opposed to only $19 \%$ in late gestation group $(p=0.002)$. The need for $2^{\text {nd }}$ dose misoprostol to complete the abortion was significantly higher in the latter group than that in the former group ( $p<0.001)$. The need for surgical intervention was comparatively less in the former group with delayed heavy bleeding being the main indication for surgical intervention. Muscle cramping and nausea/vomiting were the most noted complications and were considerably higher in the former group. A significantly higher proportion of women in the early gestation group $(17.1 \%)$ reported that the bleeding following intervention was less than they expected compared to that reported by the women of late gestation $(2.4 \%) \quad(p=0.038)$. However, pain, adverse effect and time to complete the procedure all were acceptable to the majorities of women of either group. Studies consistently show that 85-95 percent of women are satisfied or highly satisfied with the method, and would be willing to use it again if needed or recommend it to a friend if 
needed. ${ }^{14,15}$ Young women in multiple settings similarly expressed their high satisfaction with MRM $^{16-20}$ and up to 92 percent of them told that they would recommend the method to a friend. ${ }^{16}$, 20 Women often mention the non-surgical aspect of MRM, as a significant benefit over vacuum aspiration and perceive it as a more private and natural method.

Menstrual Regulation with Medication (MRM) has the potential to greatly improve access to safe abortion and may be particularly beneficial in settings where uterine evacuation services are limited or completely unavailable. MRM offers the advantages in low-resource settings or in communities where access to safe abortion is restricted and hazardous. It is simple to deliver and easy to manage. The medications do not require refrigeration, and require less equipment, facilities and staffing. The combination of mifepristone plus misoprostol is more effective in achieving complete menstrual regulation than either drug used alone. ${ }^{21,22}$ In the first trimester, the combination of mifepristone and misoprostol results in successful menstrual regulation with no need for aspiration evacuation in over 95 percent of cases. Mifepristone increases uterine sensitivity to prostaglandins (like misoprostol) and softens the cervix. Misoprostol, a synthetic prostaglandin, stimulates cervical ripening (softening) and uterine contractions, causing uterine evacuation. Misoprostol is inexpensive and available in many countries for the prevention and treatment of gastric ulcers. Although it is stable at room temperature, the potency of misoprostol can degrade over time depending on its packaging or if it is exposed to high heat or humidity. ${ }^{23}$

\section{CONCLUSION}

From the findings of the present study and discussion thereof, it is evident that MRM with misoprostol is effective in aborting the uterine content in women with early gestation (up to 42 days) with less bleeding and other complications. As the bleeding is more in women with late gestation (from 43 days to 63 days), universal recommendation of its use to women with late gestation may be risky, particularly in women living in remote rural areas or in women living in conservative society. If a woman has these specific characteristics, MRM may have higher risks than usual. The risks, benefits and availability of alternatives to MRM must be considered. MRM provision may require a higher degree of clinical judgment, skill and/or monitoring.

\section{REFERENCES}

1. Brenner WE, David AE. Menstrual regulation: Risk" and abuses. Int J Obstet Gynaecol 1977;15:77-83.

2. Amin R, Kamal GM, Marian AG. Menstrual Regulation in Bangladesh: an evaluation of training and service programs. Int J Gynaecol Obstet 1988;27(2):26571.

3. World Health Organization. Safe abortion: Technical and policy guidance for health systems, $2^{\text {nd }}$ ed. Geneva: World Health Organization. 2012.

4. Winikoff B, Dzuba IG, Creinin MD, Crowden WA, Goldberg AB, Gonzales J et al. Two distinct oral routes of misoprostol in mifepristone medical abortion: a randomized controlled trial. Obstetrics and Gynecology 2008;112(6):1303-10.

5. von Hertzen H, Piaggio G, Huong NT, Arustamyan K, Cabezas E, Gomez M et al. WHO Research Group on Postovulatory Methods of Fertility Regulation. Efficacy of two intervals and two routes of administration of misoprostol for termination of early pregnancy: a randomized controlled equivalence trial. Lancet 2007;369(9577):1938-46.

6. Hamoda $\mathrm{H}$, Templeton A. Medical and surgical options for induced abortion in first trimester. Best Practices and Research. Clinical Obstetrics and Gynaecology 2010;24(4):503-16.

7. World Health Organization. Unsafe abortion: global and regional estimates of the incidence of unsafe abortion and associated mortality in 2008. Geneva, Switzerland: World Health Organization. 2011.

8. Gynuity Health Projects. Map of misoprostol approval. New York: Gynuity. 2011.

9. Niinimäki $M$, Suhonen $S$, Mentula $M$, Hemminki $E$, Heikinheimo $O$, Gissler M. Comparison of rates of adverse events in adolescent and adult women undergoing medical abortion: Population register based study. BMJ 2011;342:d2111.

10. Warriner IK, Wang D, Huong NT, Thapa K, Tamang A, Shah I, Baird DT, Meirik O. Can midlevel health-care providers administer early medical abortion as safely and effectively as doctors? A randomized controlled equivalence trial in Nepal. Lancet 2011;377(9772):1155-61.

11. Turner $\mathrm{KL}$, Borjesson $\mathrm{E}$, Huber A, Mulligan C. Abortion care for young women: A training tool kit. Chapel Hill, NC: Ipas. 2011.

12. Murthy A, Creinin MD. Pharmacoeconomics of medical abortion: a review of cost in the United States, Europe and Asia. Expert Opinion in Pharmacotherapy 2003;4(4);503-13.

13. Creinin MD. Randomized comparison of efficacy, acceptability and cost of medical versus surgical abortion. Contraception $2000 ; 62(3): 117-24$. 
14. Winikoff B, Sivin I, Coyaji KJ, Cabezas E, Xiao B, Gu S et al. Safety, efficacy, and acceptability of medical abortion in China, Cuba, and India: a comparative trial of mifepristone misoprostol versus surgical abortion. Am J Obstet Gynecol 1997;176(2):431-7.

15. Karki C, Pokharel H, Kushwaha A, Manandhar D, Bracken $H$, Winikoff. Acceptability and feasibility of medical abortion in Nepal. International journal of gynaecology and obstetrics 2009;106(1):39-42.

16. Carbonell JL, Velazco A, Varela L, Tanda R, Sanchez C, Barambio S, Chami S, Valero F, Aragon S, Mari J. Misoprostol for abortion at 9-12 weeks' gestation in adolescents. Eur J Contracept Reprod Health Care 20016(1):39-45.

17. Creinin MD. Medically induced abortion in a woman with a large myomatous uterus. American Journal of Obstetrics and Gynecology 1996;175(5):1379-80.

18. Mamers PM, Lavelle AL, Evans AJ, Bell SM, Rusden JR, Healy DL. Women's satisfaction with medical abortion with RU486. Medical Journal of Australia 1997;167(6):316-7.
19. Phelps RH, Schaff EA, Fielding SL. Mifepristone abortion in minors. Contraception 2001;64(6):339-43.

20. Velazco A, Varela L, Tanda R, Sanchez C, Barambio S, Chami S, Valero F, Aragon S, Mari J, Carbonell JL. Misoprostol for abortion up to 9 weeks' gestation in adolescents. Eur J Contracept Reprod Health Care 2000;5(4):227-33.

21. Ngoc NT, Blum J, Raghavan S, Nga NT, Dabash R, Diop A et al. Comparing two early medical abortion regimens: mifepristone+misoprostol vs. misoprostol alone. Contraception 2011;83(5):410-7.

22. Kulier R, Kapp N, Gulmezoglu AM, Hofmeyr GJ, Cheng, Campana A. Medical methods for first trimester abortion. Cochrane Database of Systematic Reviews 2011;(11),CD002855.

23. Hall P. What do we know about the quality of misoprostol products? RHSC Membership Meeting: Addis Ababa. Unpublished Presentation. Reproductive Health Supplies Coalition (RHSC); 2011. 